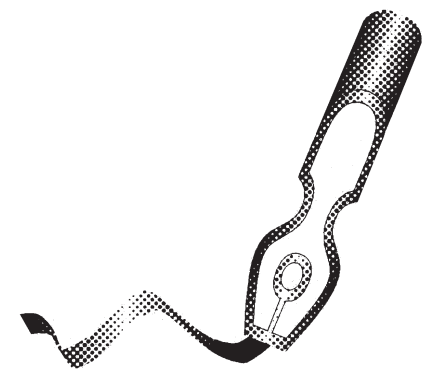

\title{
Dispositivos de ayuda auditiva: ¿Una solución para todos?
}

Según la World Health Organization (WH0, 2019) alrededor de 5\% de la población mundial padece de algún grado de hipoacusia, lo que representa cerca de 500 millones de personas. Más aún, debido al envejecimiento global, para el año 2050 estas cifras sobrepasarán los mil millones de personas, afectando por sobre todo a regiones de ingresos per cápita medios o bajos como el Sur de Asia o Sudamérica. Actualmente existen diversos tipos de dispositivos de ayuda auditiva para pacientes con hipoacusia, incluyendo audífonos, implantes cocleares e implantes de conducción ósea. Todo esto acompañado de un equipo multidisciplinario, que involucra a otorrinolaringólogos, audiólogos y foniatras entre otros profesionales; quienes junto a las tecnologías de ayuda auditiva posibilitan la rehabilitación del paciente con sordera.

El gran problema de este modelo de manejo del paciente con hipoacusia es su elevado costo. Sólo un audífono con tecnología estándar puede costar cerca de US\$1.000, mientras que un implante coclear puede llegar a un precio superior a US\$10.000. Además, se deben sumar los costes de la implementación de programas de diagnóstico audiológico, rehabilitación, entrenamiento de especialistas, remuneraciones del equipo de profesionales, entre otros. Si consideramos el creciente número de pacientes con hipoacusia que habrá en los próximos años en el mundo, es claro que los costos sobrepasarán los recursos disponibles. De esta forma, se hace necesario el replanteamiento de un nuevo modelo para el diagnóstico y tratamiento de pacientes con hipoacusia.

En 2017 la FDA aprobó la venta de audífonos over the counter, norma que debiese hacerse efectiva en Estados Unidos hacia 2020. Esto ha generado que empresas de amplificadores de audio, las cuales nunca antes se habían dedicado al desarrollo de audífonos médicos, se hayan incorporado al mercado, lo que probablemente generará una reducción del precio de los audífonos. Por otro lado, la aparición de nuevas empresas de implantes cocleares que ofrecen este tipo de dispositivos a un precio significativamente menor, hace muy probable que se genere también una caída en los precios de estos. Así, al igual que otras tecnologías -como los teléfonos celulares o computadores-, los dispositivos de ayuda auditiva deberán reducir sus precios en el corto plazo. 
La venta libre de audífonos implica riesgos que deben ser regulados. Una persona sin hipoacusia podría comprar un audífono over the counter, sin audiometría ni indicación, y sin supervisión audiológica. A todas luces, esto es peligroso para los pacientes; inclusive su mal uso podría provocar algún grado de trauma acústico. Además, con los programas de rehabilitación actuales, se sabe que cerca del $50 \%$ de los pacientes no utiliza los audífonos. Esta cifra podría ser mucho más alta en un modelo sin supervisión con audífonos de venta libre.

En un mundo que envejece, con un número creciente de pacientes con sordera, es muy probable que muchos países intenten imitar el nuevo modelo de venta de audífonos de Estados Unidos. Habrá que mantener un equilibrio entre ofrecer una solución auditiva a todos aquellos que la necesiten y la calidad del diagnóstico y rehabilitación audiológica. Para finalizar, es importante recordar que muchas de las causas de hipoacusia son potencialmente prevenibles con medidas simples y de bajo costo. Algunas de estas son: promover la vacunación contra la rubeola, parotiditis, meningitis y otros agentes patógenos; reducir la exposición al ruido, ya sea laboral o recreacional; disminuir el uso de medicamentos ototóxicos; evitar complicaciones de otitis media crónica, entre otras.

Dr. Paul Délano R.

Director

Revista de Otorrinolaringología y Cirugía de Cabeza y Cuello 